\title{
Anabases
}

ANABASES Traditions et réceptions de l'Antiquité

$26 \mid 2017$

Varia

\section{Paulo BUTTI DE LIMA, Il piacere delle Immagini. Un tema aristotelico nella riflessione moderna sull'arte}

\section{Cristina Noacco}

\section{(2) OpenEdition}

\section{Journals}

Édition électronique

URL : http://journals.openedition.org/anabases/6249

DOI : $10.4000 /$ anabases. 6249

ISSN : 2256-9421

\section{Éditeur}

E.R.A.S.M.E.

\section{Édition imprimée}

Date de publication : 1 novembre 2017

Pagination : 229-231

ISSN : 1774-4296

\section{Référence électronique}

Cristina Noacco, «Paulo BUtTI DE LIMA, I/ piacere delle Immagini. Un tema aristotelico nella riflessione moderna sull'arte », Anabases [En ligne], 26 | 2017, mis en ligne le 01 novembre 2017, consulté le 20 janvier 2021. URL : http://journals.openedition.org/anabases/6249; DOI : https://doi.org/10.4000/ anabases.6249

Ce document a été généré automatiquement le 20 janvier 2021.

(c) Anabases 


\title{
Paulo BUTTI DE LIMA, Il piacere delle Immagini. Un tema aristotelico nella riflessione moderna sull'arte
}

\author{
Cristina Noacco
}

\section{RÉFÉRENCE}

Paulo BUTTI DE LIMA, Il piacere delle Immagini. Un tema aristotelico nella riflessione moderna sull'arte, Florence, Olschki, 2012, 199 p., 23 euros / ISBN 9788822262295.

1 L'auteur se propose d'étudier l'influence que la Poétique d'Aristote a exercé sur l'art moderne et notamment le poids de la tradition, fondée sur les observations aristotéliciennes, qui considère le plaisir comme la finalité de l'art (Poétique, IV).

Dans le premier volet de son étude, l'auteur présente la «théorie» des images d'Aristote, que le philosophe posait comme fondement de la poésie. D'après ce dernier, l'homme n'éprouve pas du plaisir seulement grâce aux images de ce qui, dans la nature, est agréable, mais aussi grâce aux images de ce qui serait désagréable à voir directement. La représentation d'une expérience douloureuse ou regrettable, si elle est bien faite, offre au spectateur du plaisir, dans la mesure où elle lui permet de (re)connaître la réalité. Ainsi, l'art se charge d'une fonction gnoséologique, qui tire ses enjeux de sa distance et de sa proximité par rapport à la réalité. Mieux, l'art semble pouvoir « délivrer les hommes des expériences fastidieuses, en transformant celles-ci en source de plaisir et connaissance» (p. 9). Parmi les expériences douloureuses, Aristote donne l'exemple de " certains animaux désagréables » et des cadavres.

Dans une deuxième approche de son ouvrage, l'auteur s'intéresse aux lectures proposées, à diverses époques, de la Poétique d'Aristote. Les commentateurs ont en particulier essayé de comprendre à quels animaux le philosophe se référait lorsqu'il parlait d'animaux désagréables. $\mathrm{Si}$, jusqu'au $\mathrm{xv}^{\mathrm{e}}$ siècle, dans la droite lignée du commentaire à la Poétique d'Averroès, prévaut l'interprétation qui penche pour les 
animaux les plus bas ou les plus méprisables, comme les insectes (viliora animalia), à la fin du même siècle et pendant tout le $\mathrm{XVI}^{\mathrm{e}}$, à partir d'Andronic Calliste (qui propose de lire, à la place de atimotata theria, animaux méprisables, agriotata theria, c'est-à-dire animaux sauvages), prévaut la lecture qui penche pour les animaux les plus dangereux (ferae truculentae). L'interprétation du passage aristotélicien reste discutée tout au long des $\mathrm{XVI}^{\mathrm{e}}, \mathrm{XVII}^{\mathrm{e}}$ et $\mathrm{XVIII}^{\mathrm{e}}$ siècles, en association avec la finalité utilitariste ou hédoniste de la poésie, en référence à la poétique des images. La nature des objets représentés oppose également les auteurs au XVI ${ }^{\mathrm{e}}$ siècle : Lodovico Dolce (1500-1568) critique les nus de Michel-Ange comme "estropiés », "trop charnus", ou «secs» (p. 61), face aux formes harmonieuses et gracieuses de Raphael, tandis que Romano Alberti (1540 ? 1600 ?) affirme que plus le sujet d'une peinture est répugnant, plus il provoquera du plaisir chez le spectateur. Le plaisir de la sensation s'ajoute dès lors à celui de l'imitation et fait entrer les monstres dans la galerie des objets de la représentation. Ces diverses interprétations de la Poétique d'Aristote, influencées par l'Art poétique d'Horace, qui faisait une place à la peinture composite des animaux, ont des conséquences sur la conception de la vérité de la représentation, puisque le plaisir lié à la vue des figures fantastiques, démoniaques et monstrueuses ne peut pas être ramené à un procédé de reconnaissance de la réalité. C'est l'art du peintre, soit le niveau de vraisemblance qu'il peut atteindre, rendu indépendant du principe de reconnaissance dont parlait Aristote, qui détermine le plaisir chez le spectateur, comme le diront Nicolas Boileau (1636-1711) et l'abbé Du Bos (1670-1742): «mieux ils [les monstres etc.] sont imitez, plus nous les regardons avidement $»($ p. 93).

4 Les peintres flamands, avec leur monde pictural issu du merveilleux et de l'inconnu, nourrissent cet engouement pour le monstrueux. Afin d'expliquer les enjeux de ce nouveau parcours exégétique de la Poétique d'Aristote, dans un troisième volet de son étude, Paulo Butti de Lima s'appuie sur la représentation d'un mythe particulier, celui de Méduse, la Gorgone qui paralysait non seulement en regardant, mais aussi en étant regardée. La réflexion sur la connaissance est ici de nouveau centrale, tout comme celle sur la vérité de l'image, que Persée déjà esquivait en regardant la Gorgone non directement, mais dans l'image réfléchie par son bouclier. En particulier, Butti de Lima analyse une peinture de Rubens, Tête de Méduse, conservée au Kunsthistorisches Museum de Vienne, où le choix du peintre s'est porté non pas sur le moment crucial du mythe, la décapitation par Persée de la Gorgone, ni sur le moment qui le précède (le danger représenté par la vue de cette femme) ou qui le suit (Persée tenant la têtetrophée de Méduse dans sa main, face au public), mais sur la vision de la tête coupée posée sur un rocher, désormais dénuée de tout danger, comme pour souligner et pour valider le paradoxe aristotélicien du plaisir associé à la vision monstrueuse. Cette œuvre, ainsi que celles qu'elle inspirera, s'inscrivent dans une tradition qui, depuis la Poétique d'Aristote et l'ut pictura poesis d'Horace, ne cesse de s'interroger sur la nature de l'art en tant que connaissance, souffrance et plaisir. Par ailleurs, la leçon aristotélicienne continue de se faire entendre également dans les œuvres du XviI ${ }^{\mathrm{e}}$ siècle qui mettent en scène des leçons d'anatomie, où le plaisir lié à la représentation vraisemblable des corps sans vie est doublé par celui de la connaissance.

Le plaisir qui naît de la souffrance, voire de la contemplation de la mort, offre à l'auteur un dernier sujet de réflexion, qu'il développe dans une quatrième section du livre. La récupération de l'ancien concept du sublime au XvIII ${ }^{e}$ siècle révèle en effet les limites de l'art. Contrairement à ce qui se passe dans la Poétique, le sublime n'oppose pas une 
image plaisante à une réalité désagréable, mais il se fonde sur une réalité qui attire et effraye à la fois (p. 163). Jusqu'à quel point peut-on justifier le plaisir qui naît de la représentation de l'horrible, comme les cadavres? Paulo Butti de Lima expose l'embarras à ce sujet de Lessing et le refus, de la part de Kant, d'accueillir «l'objet répugnant parmi les formes de la représentation artistique : il demeure donc le banc d'essai de la nature de l'art» (p. 174).

6 Par l'étude diachronique de la réception de la Poétique d'Aristote, l'ouvrage de Paulo Butti de Lima offre une contribution remarquable à la réflexion moderne sur l'art, qui mériterait d'être étendue au XIX ${ }^{e}$ siècle, en incluant au moins l'apport déterminant de Baudelaire, et à l'époque contemporaine.

7 L'ouvrage est complété de quelques illustrations (que l'on aurait souhaitées plus nombreuses, en fonction des œuvres picturales citées), d'une ample bibliographie et d'un index des noms.

\section{AUTEURS}

\section{CRISTINA NOACCO}

Université Toulouse - Jean Jaurès (UT2J)

cnoacco@yahoo.fr 